\title{
A SEROPREVALENCE SURVEY OF COMMON VIRAL INFECTIONS AMONG SUSPECTED CASES ATTENDING TERTIARY CARE HOSPITAL IN AMRITSAR DISTRICT OF PUNJAB, INDIA
}

\author{
${ }^{1}$ Associate Professor, Department of Microbiology, Government Medical College, Amritsar. \\ ${ }^{2}$ Research Scientist, VRDL, GMC, Amritsar. \\ ${ }^{3}$ Assistant Professor, Department of Microbiology, Government Medical College, Amritsar. \\ ${ }^{4}$ Professor, Department of Microbiology, Government Medical College, Amritsar. \\ ${ }^{5}$ Senior Resident, Department of Microbiology, Government Medical College, Amritsar. \\ ${ }^{6}$ Research Assistant, VRDL, GMC, Amritsar, \\ ${ }^{7}$ Associate Professor, Department of Microbiology, Government Medical College, Amritsar.
}

Kanwardeep Singh ${ }^{1}$, Manpreet Kaur², Shailpreet K. Sidhu³, Pushpa Devi', Maninder Kaur ${ }^{5}$, Nachhatarjit Singh 6 , Sita Malhotra ${ }^{7}$

\begin{tabular}{l}
\hline ABSTRACT \\
BACKGROUND \\
Timely identification of an epidemic occurrence and appropriate strategies for treatment require accurate diagnosis of viral \\
diseases. However, the data for incidences of viral diseases in the northern parts of India is limited. \\
The aim of the present study was to diagnose the various occurrences and outbreaks of viral diseases mainly chikungunya, \\
cytomegalovirus, dengue, hepatitis A, B, C, E, herpes simplex 1, 2 and rubella in Amritsar and neighbouring districts of Punjab along \\
with the demographic and geographical data of the patients.
\end{tabular}

\section{MATERIALS AND METHODS}

Whole blood sera samples from a total of 6099 patients suspected of various viral diseases (chikungunya, cytomegalovirus, dengue, hepatitis A, hepatitis B, hepatitis C, hepatitis E, herpes simplex-1, 2 and rubella) were received at VRDL, GMC, Amritsar from May 2016 to December 2016. The diagnosis was based on serological assays.

\section{RESULTS}

Out of total 6099 suspected cases, 3269 were diagnosed with antibodies for at least one of the tested viral diseases. Dengue virus was the highest occurring viral disease (66\%). Male patients infected with viruses outnumbered female cases except for chikungunya, herpes simplex-1, 2 and rubella. The 21 - 40 years' age group appeared to be the most susceptible age group for nearly all studied viral infections except cytomegalovirus and hepatitis A. Among the total eight reported outbreak investigations, largest encompasses 2795 dengue cases from Amritsar district.

\section{CONCLUSION}

The significance of diagnostics is anticipated to increase with advances in interventions and health information technology. Emerging and future diagnostics will have wide-ranging impacts on all aspects of healthcare; further, they will help advance new fundamental concepts of care and improve the quality of health services.

\section{KEYWORDS}

Chikungunya, Cytomegalovirus, Dengue, Hepatitis, Herpes Simplex, Rubella, Amritsar.

HOW TO CITE THIS ARTICLE: Singh K, Kaur M, Sidhu SK, et al. A seroprevalence survey of common viral infections among suspected cases attending tertiary care hospital in Amritsar district of Punjab, India. J. Evolution Med. Dent. Sci. 2017;6(59):43474352, DOI: $10.14260 / \mathrm{Jemds} / 2017 / 940$

\section{BACKGROUND}

Regarding human health, the debilitating infectious diseases are a matter of deep concern. Numerous different strains of microbes including viruses exist in the immediate environment surrounding man, often maintained within other species without causing human disease. However, the ecological balance is often affected by various disturbances from time to time, resulting in these microbes to emerge or re-emerge in human populations and cause sporadic disease or outbreaks.[1]

Financial or Other, Competing Interest: None.

Submission 16-06-2017, Peer Review 13-07-2017,

Acceptance 19-07-2017, Published 24-07-2017.

Corresponding Author:

Manpreet Kaur

Research Scientist,

Viral Research \& Diagnostic Laboratory,

Government Medical College,

Circular Road, Amritsar, Punjab, India.

E-mail: manpreet024@gmail.com

DOI: $10.14260 /$ jemds $/ 2017 / 940$
The emerging infectious diseases account for nearly $30 \%$ of annual deaths worldwide, despite the availability of various antimicrobials and vaccines.[2] The morbidity and mortality associated with infectious diseases far more exceeds in developing countries. Various factors like favourable environment, demographics and socio-economic status put India as the second most populous country in the world at a risk of epidemics of emerging infections.[3]

It has been well documented that $37 \%$ of emerging and re-emerging pathogens are viruses.[3-4] Diagnosis is one of the prime requirements in disease management. Definitive diagnosis of viral diseases is essential for recognising the occurrence of epidemics and for instituting appropriate treatment.[5] These can provide strong evidence linking exposure to the incidence of infection or disease in a population and can also provide estimates of the magnitude of risk related to a particular level of exposure, therefore can be used in the evaluation of appropriate microbiological quality guideline levels or standards. There are, however, very limited studies reporting the incidences of viral diseases in the northern parts of India. ${ }^{[6-9]}$ With this perspective the 
present study was conducted to diagnose the various occurrences and outbreaks of viral diseases mainly chikungunya, cytomegalovirus, dengue, hepatitis A, B, C, E, herpes simplex 1, 2 and rubella, in Amritsar and neighbouring districts of Punjab along with the demographic and geographical data of the patients.

\section{MATERIALS AND METHODS}

The blood samples were collected for this descriptive study from patient suspected of chikungunya, cytomegalovirus, dengue, hepatitis $A$, hepatitis $B$, hepatitis $C$, hepatitis $E$, herpes simplex and rubella visiting the Guru Nanak Dev Hospital (affiliated to Government Medical College (GMC), Amritsar (Punjab), India) were received at the Viral Research and Diagnostics Laboratory (VRDL) located at GMC, Amritsar, for a period from May 2016 till December 2016. All the samples were accompanied with demographic and geographical details of the patient. Patients of all age groups with positive viral infection based on serological assays (enzyme-linked immunosorbent assay (ELISA) test) were included in the present study. Patients with positive viral antibodies, but residing outside Punjab were excluded.

About $5 \mathrm{~mL}$ of whole blood sera were received in an ice box maintained at $2-8^{\circ} \mathrm{C}$ and processed within $24-48$ hours. The samples were tested for IgM antibodies of chikungunya virus (ChikV, ELISA kit received from NIV, Pune), cytomegalovirus (CMV, Make: CALBIOTECH, CA, USA), dengue virus (DenV, ELISA kit received from NIV, Pune), hepatitis A virus (HAV, Make: DiaPro, Milan, Italy), hepatitis E virus (HEV, Make: DiaPro, Milan, Italy), Herpes Simplex Virus (HSV, Make: CALBIOTECH, CA, USA) and rubella virus (Make: CALBIOTECH, CA, USA) using IgM antibody capture ELISA kits. For patients suspected of DenV infections non-structural protein 1 (NS-1, Make: InBios, Washington, USA) antigen (fever $<5$ days) was also performed. The presence of Australian antigen (HBsAg, Make: J. Mitra, New Delhi, India) and anti-HBc (Make: BIORAD, Gurgaon, India) IgM antibodies was tested for hepatitis B suspected samples, while hepatitis C virus (HCV, Make: SD, Republic of Korea) testing was done for presence of IgG antibodies. All the tests were carried out following the manufacturer's instructions.

\section{Statistical Analysis}

The data was evaluated using Microsoft Office Excel worksheet and percentage and proportions for every variable was calculated.

\section{Ethical Compliance}

All procedures followed were in accordance with the ethical standards of the responsible committee on human experimentation (Institutional and National) and with the Helsinki Declaration of 1975, as revised in 2000. Informed consent was obtained from all patients for being included in the study.

\section{RESULTS}

In the present study a total of 6099 subjects suspected for ChikV, CMV, DenV, HAV, HBV, HCV, HEV, HSV1, 2 and rubella have been tested and out of these 3269 cases have been reported to be positive for one or more of these viral infections (Table 1). It is noteworthy that the DenV is predominant in the studied districts with a total of 2178 subjects presenting the anti-DenV antibodies. It is followed by HCV (840), ChikV (127), HEV (63), HSV (22), CMV (18), HBV (13), HAV (7) and rubella (1).

Table 2 presents the baseline demographic characteristics of the studied subjects. The male group had higher prevalence of almost all the studied viruses; CMV (89\%), DenV (64\%), HAV (71\%), HBV (89\%), HCV (74\%) and HEV (65) as compared to their female counterparts except ChikV (46\%), HSV (40\%) and rubella (100\%). The mean age laid between 20.43 years (HAV) and 46.80 years (CMV).

It is evident in Table 3 that the youngest age group $(0-20$ years) presented with very few cases of all viral infections except HAV (4 out of 9). The 21 - 40 years' group appeared to be the most susceptible age group for nearly all the studied viral infections (ChikV-60, DenV-995, HCV-462, HEV-54, HSV15 , rubella-1). A significant number of cases of CMV have been reported in the older age groups $(41-60 \mathrm{yrs}$ - 7 and > 60 yrs. - 7), also HBV was most prevalent in $>60$ years' age group (13 out of 26 ).

Suspected samples have been received from Amritsar, Gurdapur, Hoshiarpur, Pathankot, Tarn Taran and Jalandhar districts. In addition, few random cases have also been received from other districts such as Kapurthala, Ferozepur, Ludhiana, Moga and Patiala which have been clubbed together as 'others' group. A district-wise distribution of positive cases for tested viruses has been presented in Figure 2. It has been observed that maximum cases of all the viral infections ChikV, CMV, DenV, HAV, HBV, HCV, HEV, HSV and rubella have been reported from Amritsar district followed by Gurdaspur. However, significant number of HCV patients have been reported from Tarn Taran.

The present study reports a total of eight outbreaks comprising of ChikV, DenV, HAV and HEV epidemics in the studied population. The largest outbreak encompassing 1975 DenV cases (as multiple outbreaks) was diagnosed from the Amritsar district. The DenV outbreak in Gurdaspur followed by 105 cases. The ChikV outbreak in Amritsar was the next significant occurrence with 72 cases. HEV outbreak also occurred in Amritsar (4 out of 5 suspected patients) during the study period.

\begin{tabular}{|c|c|c|}
\hline Virus & $\begin{array}{c}\text { Total Suspected } \\
\text { Cases }\end{array}$ & $\begin{array}{c}\text { Total Positive } \\
\text { Cases }\end{array}$ \\
\hline CHIKV & 373 & 127 \\
\hline CMV & 34 & 18 \\
\hline DENV & 3160 & 2178 \\
\hline HAV & 134 & 7 \\
\hline HBV & 648 & 13 \\
\hline HCV & 1561 & 840 \\
\hline HEV & 134 & 63 \\
\hline HSV & 53 & 22 \\
\hline Rubella & 2 & 1 \\
\hline Total & 6099 & 3269 \\
\hline \multicolumn{2}{|c|}{ Table 1. Distribution of Serologically Tested } \\
Positive Cases out of the Total Suspected Subjects \\
\hline
\end{tabular}




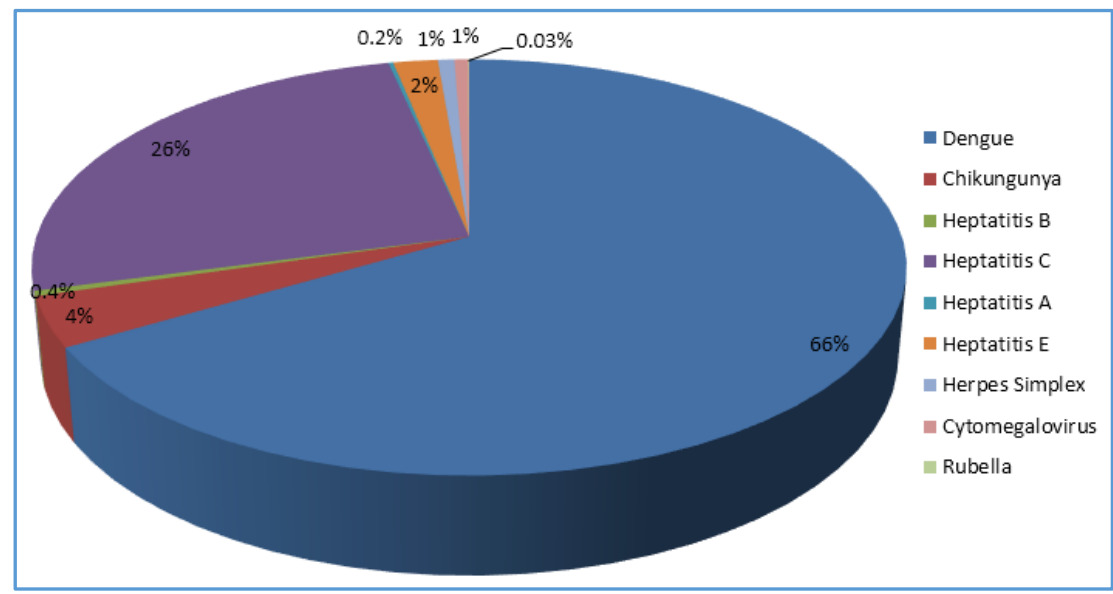

Figure 1. Pie Chart presenting Percentage of Subjects Tested Positive for each of the Studied Viral Infection

\begin{tabular}{|c|c|c|c|c|c|c|c|c|c|}
\hline Parameter & CHIKV & CMV & DENV & HAV & HBV & HCV & HEV & HSV & Rubella \\
\hline $\mathbf{N}$ & 127 & 18 & 2178 & 7 & 13 & 840 & 63 & 22 & 1 \\
\hline \multicolumn{10}{|c|}{ Sex } \\
\hline Male (\%) & $58(46)$ & $16(89)$ & $1386(64)$ & $5(71)$ & $12(89)$ & $621(74)$ & $41(65)$ & $9(40)$ & $0(00)$ \\
\hline Female (\%) & 69 (54) & $2(11)$ & $792(36)$ & $2(29)$ & $1(11)$ & $219(26)$ & 22 (35) & $13(60)$ & $1(100)$ \\
\hline \multicolumn{10}{|c|}{ Age } \\
\hline Mean & 35.18 & 46.80 & 35.28 & 20.43 & 30.11 & 39.05 & 31.47 & 34.10 & 28 \\
\hline SD & 14.14 & 26.66 & 16.06 & 12.23 & 11.32 & 13.90 & 11.29 & 14.05 & 0.00 \\
\hline Range & $14-75$ & $8-72$ & $1-90$ & $8-45$ & $20-54$ & $4-80$ & $2-60$ & $18-65$ & 28 \\
\hline \multicolumn{10}{|c|}{ Table 2. Baseline Demographic Characteristics of the Surveyed Patients } \\
\hline
\end{tabular}

\begin{tabular}{|c|c|c|c|c|}
\hline Virus & $\mathbf{0 - 2 0}$ & $\mathbf{2 1 - 4 0}$ & $\mathbf{4 1 - 6 0}$ & $\mathbf{> 6 0}$ \\
\hline CHIKV & 23 & 60 & 41 & 3 \\
\hline CMV & 4 & 0 & 7 & 7 \\
\hline DENV & 429 & 995 & 598 & 156 \\
\hline HAV & 4 & 3 & 1 & 1 \\
\hline HBV & 1 & 11 & 1 & 0 \\
\hline HCV & 34 & 462 & 280 & 65 \\
\hline HEV & 8 & 54 & 15 & 2 \\
\hline HSV & 2 & 15 & 2 & 2 \\
\hline Rubella & 0 & 1 & 0 & 0 \\
\hline \multicolumn{5}{|c|}{ Table 3. Age-Wise Distribution of } \\
\hline
\end{tabular}

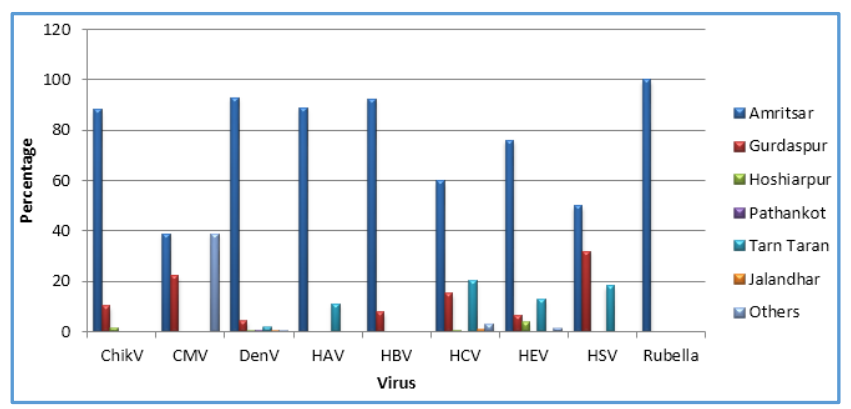

Figure 3. Percentage of Positive Cases Detected from various Surveyed Districts

\begin{tabular}{|c|c|c|c|c|}
\hline District & $\begin{array}{c}\text { Outbreak } \\
\text { ID }\end{array}$ & $\begin{array}{c}\text { No. of } \\
\text { Patients }\end{array}$ & $\begin{array}{c}\text { Virus } \\
\text { Tested }\end{array}$ & $\begin{array}{c}\text { Positive } \\
\text { Cases }\end{array}$ \\
\hline Tarn Taran & 1 & 5 & HAV & 0 \\
\cline { 3 - 5 } & & HEV & 4 \\
\hline Amritsar & 2 & 2795 & DenV & 1975 \\
\hline Gurdaspur & 3 & 186 & DenV & 105 \\
\hline Tarn Taran & 4 & 88 & DenV & 58 \\
\hline Pathankot & 5 & 67 & DenV & 42 \\
\hline Hoshiarpur & 6 & 10 & DenV & 4 \\
\hline Amritsar & 7 & 185 & ChikV & 72 \\
\hline Gurdaspur & 8 & 22 & ChikV & 10 \\
\hline
\end{tabular}

Table 4. Number of Outbreaks Investigated

\section{DISCUSSION}

Many of the diseases that have emerged or re-emerged in India in recent years are caused by viruses. High rates of mutation and antigenic change along with rapid adaptation to newer ecosystems makes them efficient at infecting new hosts including man, thus creating local or global health 
threats. This is especially true of viruses that contain Ribonucleic Acid (RNA), as these mutate rapidly during replication and exhibit tremendous genetic plasticity due to the built-in advantages provided by their error prone replicative enzymes and ability to genetically reassort (when their genome is segmented) or recombine.[1] India the second most populous country in the world is in the midst of a triple burden of diseases; the unfinished agenda of communicable diseases, non-communicable diseases linked with lifestyle changes and emergence of new pathogens and overstretched health infrastructure. ${ }^{[3]}$

In the period from May 2016 till December 2016, the present study reports that the number of patients visiting the hospital with symptoms for Dengue, Chikungunya, Hepatitis C and Hepatitis $\mathrm{E}$ outnumbered other viral diseases. It has been observed that maximum cases of chikungunya (ChikV), cytomegalovirus (CMV), dengue (DenV), hepatitis A (HAV), hepatitis B (HBV), hepatitis C (HCV), hepatitis E (HEV), herpes simplex (HSV) and rubella have been reported from Amritsar district.

It is reported that dengue has been endemic in 16 states of India including Punjab since the beginning in 2007. Although, the number of dengue cases has shown a steady rise with every passing year, the mortality has reduced.[10] With respect to chikungunya (first outbreak recorded in Kolkata in 1963) the year 2011 was exceptional, in that cases were reported from all states except Punjab, Dadra and Nagar Haveli and Lakshadweep. First case of Chikungunya was reported from Punjab in Ferozepur in 2010. The case was an imported case of Chikungunya from Delhi.[10]

In comparison to an earlier study from same laboratory ${ }^{[8]}$ that received only 20 chikungunya suspected cases and 2709 dengue suspected cases, the present study received 373 chikungunya suspected cases (127 positive) and 3160 dengue suspected cases (2178 positive) from May 2016 till December 2016. This is much higher than many other Indian studies.[11] It indicates an increase in dengue virus activity, raising the question whether dengue is emerging/re-emerging as a major health problem in Amritsar. This also shows the improvement at clinical diagnosis level in differentiating between chikungunya and dengue infections.[12-13]

The ChikV was slightly more prevalent in females (54\%) as compared to the males (46\%) supported by other findings by Balasubramaniam et al[14] and Dwibedi et al,[15] but in contrast with the pattern seen be Kalawat et al[16] and Singh et al.[8] However, the males (64\%) outnumbered females $(36 \%)$ in Den V positivity. Similar pattern observed by other researchers.[8,17-20] However, this may be the representation of all the patients who visited the healthcare system to seek medical care rather than the truly infected population. For both the infections adult age group, 21 - 40 years $(60 / 127$ chikV positive cases and 995/2178 dengue positive cases) appeared to be most susceptible age group. Similar findings were observed in the study done by Singh et al,[8] Sandhya BK

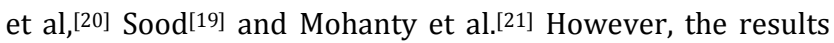
contradicted with some of the studies done elsewhere in India, who reported the paediatric age group as the most vulnerable when compared with adults. ${ }^{[22-23]}$

CMV is found universally throughout all the geographical locations and in the areas of low socioeconomic conditions. A majority of these infections are asymptomatic as others and they are difficult to diagnose clinically.[24] This study showed a seropositive rate of $52.9 \%$ for the CMV specific IgM, thus indicating a higher prevalence in and around Amritsar. Age is one of the factors affecting the prevalence of CMV antibodies in a community. In our study, seropositivity was observed to be maximum in age group $>40$ years $(77 \%)$. These findings are in accordance with other studies from India and abroad.[24] As no effective treatment and vaccine against the CMV is available, more emphasis should be laid upon educating people (to maintain good hygiene, limited contact with infected children and responsible sexual practices) and their prospective screening to reduce the foeto-maternal transmission.

The incidence of HAV and HEV infections is higher in individuals inhabiting crowded living conditions and in areas of low socioeconomic development. A chronic carrier state does not occur in patients infected with HAV or HEV. These two types of hepatitis are maintained in a population by serial transmission from subclinically infected persons to susceptible persons ${ }^{[25]}$ and contamination of municipal water supplies by the sewerage.

The Punjab is generally considered an area of low endemicity for hepatitis $\mathrm{A}$ and $\mathrm{E}$ in comparison to other Indian states. In the current study the seroprevalence of HAV was $5.22 \%$ (7 out of 134 suspected cases) and HEV prevalence was considerably reduced from $74.47 \%$ in the past ${ }^{[8]}$ to $47.76 \%$ (63 out of 134 suspected cases) in the present study. The trend of the decrease in the prevalence is in accordance with shifting patterns of sero-prevalence over the past 20 years seen in South-East Asia and China that reflected improved living standards and environmental hygiene.[8,26-27]

Sex wise distribution shows that males have higher incidence of HAV (71\%) than females (29\%). This might be because major route of transmission of HAV is feco-oral route with poor sanitation and contaminated food/water supplies and as male go out more for work, so chances of eating outside also increase as shown by other studies.[6,28] Early studies of HAV seroprevalence in India showed that $90 \%$ of Indian children in the age group of 5 - 10 years had anti-HAV antibodies.[29] The present data shows that anti-HAV antibody prevalence is the highest $(77.77 \%)$ in younger age groups $(0$ 20 years: $44.4 ; 21$ - 40 years: 33.3 ). It is in contrast to studies reported recently from other Indian states, which showed much lower anti-HAV positivity rates.[30-31] HEV mainly affects young adults of 21 - 40 years of age and relatively spares children ( $<20$ years) (Aggarwal and Krawczynski, 2000).[32] The results of the present epidemiological study show the presence of an overall high endemicity of HEV infection (68.358\%) and a significantly lower seroprevalence in the age groups $<20$ years and $>40$ years. Similar findings were reported by other researchers Arora et al(2013) ${ }^{[6]}$ and Singh et al(2016).[8] This was in sharp contrast to few other studies (Aggarwal et al 1997; Murhekar et al 2002).[33-34] These differences might be due to either varying environmental conditions in different geographical areas or the differences in the diagnostic tests used. The Tarn Taran district encountered one predominant outbreak for HEV (4 out of 5 suspected cases).

Hepatitis B and C are found throughout the world, they have no seasonal distribution. The reported prevalence of HBV carrier in different population varies widely from $0.1 \%$ in the advanced countries to $20 \%$ in the developing nations. 
The current study shows $2.0 \%$ (13 out of 648) seroprevalence of HBV among suspected cases visiting the hospital. The frequency of HBV seropositivity has been found to be lower than that reported in other studies (Hussain et al 1991; Sumathy et al 1992).[35-36] General prevalence of HCV is $0.5 \%$ to $1 \%$ and there are about 15 million HCV carriers in India (Chaterjee and Sen, 2006).[37] Prevalence of anti-HCV in blood donors in developed countries range from $0.4-2 \%$ (Bhardwaj et al 2013).[38] The seroprevalence of HCV in present study is $53.8 \%$ of the total suspected cases visiting the hospital. The reason for such observation is probably the free drug initiative by Punjab government under "Mukh Mantri Punjab Hepatitis-C Relief Fund Scheme (MMPHRF)." At present the mode of treatment is passive under which patients are already aware of their status of Hepatitis C reporting to public hospitals are being initiated on treatment. This led to a sudden hike in the number of patients being diagnosed with anti-HCV antibodies, although the true positive new cases would be far lower than this.

With respect to sex related prevalence, the male group had predominance of both HBV (89\%) and HCV (82.5\%). These findings are supported by number of other Indian studies (Chaudhary et al 2007; Jain et al 2013; Singh et al 2016).[8,39-40] The present study reveals that HBV and HCV prevalence was highest in adult age group, 21 - 40 years. This is comparable with some other Indian studies (James et al 2001).[41] Use of unsterilised kits for vaccinations may be one reason for higher prevalence in older age groups. Since immunisation against hepatitis B was recently introduced, the older age group population has a higher HBsAg prevalence, presumptively due to lack of immunisation against the disease in their times. In the present study, declining seropositive rates in individuals aged 41 years or over was observed for both genders. Self-selection due to persistent HBV/HCV infection may partly account for such tendencies (James et al 2001).[41]

Infections due to Herpes Simplex Virus (HSV) are extremely common. In the current study HSV has been detected in $41.5 \%$ of suspected cases. The higher seropositivity of HSV in females $(60 \%)$ is in concordance with previous study (Singh et al 2016).[8] HSV seropositivity is highest in the young age group of 21 - 40 years, because of their sexually active life (Venkitaraman et al 1986).[42] Adolescents are known to be at increased risk of acquiring HSV infections because of fewer protective antibodies (Agarwal and Gupta, 2000).[43] Similar results are reported by another study (Malkin et al 2002).[44]

The presence of the rubella IgM antibodies was found in 1 (out of 2 suspected cases) female in the age group of 21 - 40 years. The paradox lies in the fact that a large proportion of the cases are subclinical and that the clinical diagnosis is unreliable. Moreover, the study is limited by a single positive rubella case, so the results remain inconclusive until more number of rubella antibody positive cases are detected from the population.

\section{CONCLUSION}

Communicable diseases account for nearly half of India's disease burden. Many infections are associated with poor sanitation, contaminated food, inadequate personal hygiene or access to safe water and lack of basic health services conditions common to large parts of India. Each diagnostic method has the potential to influence patient health outcomes and facilitate informed clinical decisions. The significance of diagnostics is anticipated to increase with advances in interventions and health information technology. Emerging and future diagnostics will have wide-ranging impacts on all aspects of healthcare; further, they will help advance new fundamental concepts of care and improve the quality of health services. Early adequate information and capacity to diagnose the viruses will lead to saving of many lives.

\section{REFERENCES}

[1] Mohapatra S, Dar L. Emerging and remerging viral infections in India. JIMSA 2010;23(1):37-40.

[2] World Health Organization. Regional office for South East 4. Asia region. Combating emerging infectious diseases in the South-East Asia Region. New Delhi: World Health Organization, WHO SEARO 2005.

[3] Dikid T, Jain SK, Sharma A, et al. Emerging \& reemerging infections in India: an overview. Indian J Med Res 2013;138:19-31.

[4] Woolhouse MEJ, Gowtage-Sequeria S. Host range and emerging and reemerging pathogens. Emerg Infect Dis 2005;11(12):1842-7.

[5] Gopal S. Diagnosis of viral diseases in India: at the cross roads. J Clin Sci Res 2012;1:155-6.

[6] Arora D, Jindal N, Shukla RK, et al. Water borne hepatitis A and hepatitis E in Malwa region of Punjab, India. J Clin Diagn Res 2013;7(10):2163-6.

[7] Sidhu SK, Singh K, Devi P, et al. Clinicalepidemiological profile and diagnosis of influenza a H1N1 cases by real time RTPCR at a tertiary care institute of India: the war is not over yet. Asian Pacific Journal of Health Sciences 2016;3(3):120-5.

[8] Singh K, Sidhu SK, Devi P, et al. Seroprevalence of common viral diseases: a hospital based study from Amritsar, India. Journal of Clinical and Diagnostic Research 2016;10(12):DC15-9.

[9] Kaur M, Sidhu SK, Singh K, et al. Hepatitis E virus: A leading cause of waterborne viral hepatitis in Northwest Districts of Punjab, India. Journal of Laboratory Physicians 2017;9(2):121-4.

[10] Cecilia D. Current status of dengue and chikungunya in India. WHO South-East Asia J Public Health 2014;3(1):22-7.

[11] Ukey PM, Bondade SA, Paunipagar PV, et al. Study of seroprevalence of dengue fever in central India. Indian J Community Med 2010;35(4):517-9.

[12] Beltrame A, Angheben A, Bisoffi Z, et al. Imported chikungunya infection, Italy. Emerg Infect Dis 2007;13(8):1264-6.

[13] Nicoletti L, Ciccozzi M, Marchi A, et al. Chikungunya and dengue viruses in travelers. Emerg Infect Dis 2008;14(1):177-8.

[14] Balasubramaniam SM, Krishnakumar J, Stephen T, et al. Prevalence of chikungunya in urban field practice area of a private medical college, Chennai. Indian J Community Med 2011;36(2):124-7. 
[15] Dwibedi B, Sabat J, Mahapatra N, et al. Rapid spread of chikungunya virus infection in Orissa: India. Indian J Med Res 2011;133(3):316-21.

[16] Kalawat U, Sharma KK, Reddy SG. Prevalence of dengue and chickungunya fever and their co-infection. Indian J Pathol Microbiol 2011;54(4):844-6.

[17] Chakravarti A, Arora R, Luxemburger C. Fifty years of dengue in India. Trans $\mathrm{R}$ Soc Trop Med Hyg 2012;106(5):273-82.

[18] Gill PS, Mittal S, Bala K, et al. Recent trend of seroprevalence of dengue in Haryana. Int J Pharm Med Bio Sc 2013;2(4):44-51.

[19] Sood S. A hospital based serosurveillance study of dengue infection in Jaipur (Rajasthan), India. J Clin Diagn Res 2013;7(9):1917-20.

[20] Sandhya BK, Sastry AS, Senthamarai S, et al. Seroprevalence of dengue viral infection in patients attending to a tertiary care hospital in Kanchipuram, Tamil Nadu, India. Int J Res Health Sci 2014;2(3):81822.

[21] Mohanty I, Dash M, Sahu S, et al. Seroprevalence of chikungunya in Southern Odisha. J Fam Med Primary Care 2013;2(1):33-6.

[22] Dash PK, Parida MM, Saxena P, et al. Reemergence of dengue virus type-3 (subtype-III) in India: implications for increased incidence of DHF and DSS. Virol J 2006;3:55.

[23] Gunashekharen P, Kaveri K, Mohana S, et al. Dengue disease status in Chennai (2006-2008): a retrospective analysis. Ind J Med Res 2011;133(3):322-5.

[24] Sheevani, Jindal N, Aggarwal A. A pilot seroepidemiological study of cytomegalovirus infection in women of child bearing age. Indian J Med Microbiol 2005;23(1):34-6.

[25] Vitral CL, da Silva-Nunes M, Pinto MA, et al. Hepatitis A and $\mathrm{E}$ seroprevalence and associated risk factors: a community-based cross-sectional survey in rural amazonia. BMC Infect Dis 2014;14:458.

[26] Barzaga BN. Hepatitis A shifting epidemiology in South-East Asia and China. Vaccine 2000;18 Suppl 1:S61-4.

[27] Acharya SK, Batra Y, Bhatkal B, et al. Seroepidemiology of hepatitis a virus infection among school children in Delhi and North Indian patients with chronic liver disease: implications for HAV vaccination. J Gastroenterol Hepatol 2003;18(7):822-7.

[28] Rao P, Shenoy SM, Baliga S, et al. Prevalence of HAV and HEV in the patients presenting with acute viral hepatitis. BMC Infect Dis 2012;12(Suppl 1):30.

[29] Tandon BN, Gandhi BM, Joshi YK. Etiological spectrum of viral hepatitis and prevalence of markers of hepatitis A and B virus infection in north India. Bull WHO 1984;62(1):67-73.
[30] Das K, Kar P, Chakravorty A, et al. Is a vaccination program against hepatitis a needed in India? Indian J Gastroenterol 1998;17(4):158.

[31] Dhawan PS, Shah SS, Alvares JF, et al. Seroprevalence of hepatitis A virus in Mumbai and immunogenicity and safety of hepatitis A vaccine. Indian J Gastroenterol 1998;17(1):16-8.

[32] Aggarwal R, Krawczynski K. Hepatitis E: an overview and recent advances in clinical and laboratory research. J Gastroenterol Hepatol 2000;15(1):9-20.

[33] Aggarwal R, Shahi H, Naik S, et al. Evidence in favour of high infection rate with hepatitis E virus among young children in India. J Hepatol 1997;26(6):1425-6.

[34] Murhekar MV, Sehgal SC, Murhekar KM, et al. Changing scenario of hepatitis A virus and hepatitis E virus exposure among the primitive tribes of Andaman and Nicobar Islands, India over the 10-year period 198999. J Viral Hepat 2002;9(4):315-21.

[35] Hussain AI, Rajendran P, Thyagarajan SP. HBsAg and HIV antibody in tribal populations HBsAg and HIV antibody in tribal populations of Tamilnadu, India. Virus Inf Exch New Lett 1991;8:62.

[36] Sumathy S, Thyagarajan SP, Latif R, et al. A dipstick immunobinding enzyme-linked immunosorbent assay for serodiagnosis of hepatitis B and delta virus infections. J Virol Methods 1992;38(1):145-52.

[37] Chaterjee $K$, Sen A. Infectious laboratory markers. Jaypee Brothers, New Delhi 2006;1:101-2.

[38] Bhardwaj K, Prasad KM, Bhardwaj R, et al. Seroprevalenceof HBs Ag and HCV in healthy blood donors at a tertiary care hospital in India. RJPBCS 2013;4(4):1272-8.

[39] Chaudhary IA, Samiullah, Khan SS, et al. Seroprevalence of hepatitis B and C among health blood donors at fauji foundation hospital, Rawalpindi. Pak Med J 2007;23(1):64-7.

[40] Jain P, Prakash S, Gupta S, et al. Prevalence of hepatitis A virus, hepatitis $B$ virus, hepatitis $C$ virus, hepatitis D virus and hepatitis $\mathrm{E}$ virus as causes of acute viral hepatitis in North India: a hospital based study. Indian J Med Microbiol 2013;31(3):261-5.

[41] James L, Fong CW, Foong BH, et al. Hepatitis B seroprevalence study 1999. Singapore Med J 2001;42(9):420-4.

[42] Venkitaraman AR, Seigneurin JM, Lenoir GM, et al. Infections due to the human herpesviruses in southern India: a seroepidemiological survey. Int J Epidemiol 1986;15(4):561-6.

[43] Agarwal N, Gupta S. Reproductive tract infection in adolescent females. Obs Gynae Today 2000;5(7):4102.

[44] Malkin JE, Morand P, Malvy D, et al. Seroprevalence of HSV-1 and HSV-2 infection in the general French population. Sex Transm Infect 2002;78(3):201-3. 